\title{
SKILL OF CADRE IN DETERMINING PLOTTING POINT ON GROWTH CHART ACCORDING TO CHARACTERISTICS, SOURCE INFORMATION AND KNOWLEDGE OF CADRE
}

\author{
Titus Priyo Harjatmo, Agni Nur Imanti \\ Jurusan Gizi, Politeknik Kesehatan Kemenkes Jakarta II, \\ Jln. Hang Jebat III Blok F3 Kebayoran Baru DKI Jakarta, Kode Pos 12120 \\ E-mail: titoespriyo@yahoo.co.id
}

\begin{abstract}
Children are the next generation for a nation. Therefore a child must be prepared early on both mentally, socially and spiritually. Expected of the growth and Development can be optimal. To obtain optimal growth and development of the role of nutrition is very decisive. Posyandu is defined as a basic health activity organized from, by and for communities assisted by health workers. One of the Posyandu activities is to monitor the growth of children under five with KMS tools. If a Posyandu cadre has not understood the tendency of growth chart of KMS ,it will have an impact on the result of growth status of the child. The study conducted at one posyandu in Ciracas in East Jakarta on 33 Posyandu cadres showed that most of the cadres were unskilled in plotting the growth chart by $60.6 \%$ and the skilled $39.4 \%$. Most cadres have female sex (97.0\%), age of cadre most age 46-65 year that is 17 cadre (51.3\%), long become cadre most 6-10 year 19 cadre (57.6\%). While the highest level of cadre education is the basic education cadres of 15 cadres (44.1\%), who have attended training on KMS only 16 cadres (48.5\%), knowledge of cadres is mostly medium knowledge of 15 cadres (45.5\%). From the results of the analysis shows that cadre skills depend on cadre knowledge. Suggestions for improving skills are the necessity of holding the rotating duties so that each cadre is skilled in carrying out the growth measurement path. For Puskesmas, it is necessary to hold regular training or refresher about Posyandu activity especially KMS plotting.
\end{abstract}

Key Words: Care, growth standar, kader, standar pertumbuhan, skill

\section{KETRAMPILAN KADER DALAM MENENTUKAN TITIK PLOTTING PADA GRAFIK PERTUMBUHAN BALITA STANDART BARU MENURUT KARAKTERISTIK, SUMBER INFORMASI DAN PENGETAHUAN KADER}

\begin{abstract}
ABSTRAK
Anak merupakan generasi penerus bagi suatu bangsa. Oleh sebab itu seorang anak harus dipersiapkan secara dini baik mental, sosial dan spiritualnya. Diharapkan kualitas tumbung kembang dapat optimal. Untuk memperoleh tumbuh kembang yang optimal maka peranan gizi sangat menentukan. Posyandu diartikan sebagai kegiatan kesehatan dasar yang diselenggarakan dari, oleh dan untuk masyarakat yang dibantu oleh petugas kesehatan. Salah satu Kegiatan Posyandu salah satunya adalah memantau pertumbuhan Balita dengan alat bantu KMS. Apabila seorang kader Posyandu belum memahami mengenai kecenderungan grafik pertumbuhan Balita dalam KMS maka akan berdampak pada hasil status pertumbuhan anak tersebut. Penelitian dilakukan di salah satu posyandu di Ciracas Jakarta Timur terhadap 33 kader Posyandu menunjukkan bahwa sebagian besar kader tidak terampil dalam melakukan ploting grafik pertumbuhan sebesar 60,6\% dan yang terampil 39,4\%. Sebagian besar kader mempunyai jenis kelamin perempuan (97.0\%), usia kader terbanyak usia 46-65 tahun yaitu 17 kader (51.3\%), lama menjadi kader sebagian besar 6-10 tahun yaitu 19 kader (57.6\%). Sedangkan tingkat pendidikan kader terbanyak adalah tamatan pendidikan dasar 15 kader (44.1\%), yang pernah mengikuti pelatihan mengenai KMS hanya 16 kader (48.5\%), pengetahuan kader sebagian besar adalah berpengetahuan sedang yaitu 15 kader (45.5\%). Dari hasil analisis menunjukkan bahwa ketrampilan kader tergantung dengan pengetahuan kader. Saran untuk meningkatkan ketrampilan adalah perlu diadakannya tugas bergilir agar setiap kader terampil dalam melakukan alur pengukuran pertumbuhan. Bagi Puskesmas perlu diadakannya pelatihan atau penyegaran secara rutin mengenai kegiatan Posyandu khususnya cara pengisian KMS.
\end{abstract}

KataKunci:kader, standar pertumbuhan, ketrampilan kader 


\section{PENDAHULUAN}

Anak merupakan generasi yang akan menentukan kemajuan dan keberlangsungan bangsa. Sebagai generasi penerus bangsa, anak harus dipersiapkan sejak dini dengan upaya yang tepat, terencana, intensif dan berkesinambungan agar tercapai kualitas tumbuh kembang fisik, mental, sosial, dan spiritual tertinggi. Salah satu upaya mendasar untuk menjamin pencapaian tertinggi kualitas tumbuh kembangnya sekaligus memenuhi hak anak adalah agar peningkatan berat badan anak bisa memenuhi standar yang cukup.(1)

Pada bayi dan anak, kekurangan gizi akan menimbulkan gangguan pertumbuhan dan perkembangan yang apabila tidak diatasi secara dini dapat berlanjut hingga dewasa. Usia 6 - 59 bulan merupakan masa pertumbuhan dan perkembangan yang pesat, sehingga kerap diistilahkan sebagai periode emas sekaligus periode kritis. Periode emas dapat terwujudkan apabila pada masa ini bayi dan anak memperoleh asupan gizi yang sesuai untuk tumbuh kembang optimal. Sebaliknya apabila bayi dan anak pada masa ini tidak memperoleh peningkatan berat badan, maka periode emas akan berubah menjadi periode kritis yang akan mengganggu tumbuh kembang bayi dan anak, baik pada masa ini maupun masa selanjutnya(2)

Menurut data Riskesdas 2013 (3) secara nasional prevalensi berat-kurang adalah $19,6 \%$ yang terdiri dari 5,7\% gizi buruk dan $13,9 \%$ gizi kurang. Jika dibandingkan dengan angka prevalensi nasional tahun 2007 $(18,4 \%)$ dan tahun $2010(17,9 \%)$ terlihat meningkat. Dan menurut Tim Pemantauan Status Gizi tahun 2014 prevalensi gizi buruk di DKI Jakarta sendiri adalah sebesar $2 \%$ dan kurang 1,3\% . Hal ini menunjukkan bahwa Jakarta sendiri masih memiliki balita gizi buruk dan kurang (4).

Posyandu merupakan salah satu bentuk partisipasi masyarakat yang memberikan pelayanan dan pemantauan kesehatan yang dilaksanakan secara terpadu. Kegiatan posyandu dilakukan oleh dan untuk masyarakat, Posyandu sebagai wadah peran serta masyarakat, yang menyelenggarakan kegiatan meliputi keluarga berencana, kesehatan ibu dan anak, imunisasi, penanggulangan diare dan pendidikan gizi masyarakat.(5)

Menurut data Kementerian Kesehatan tahun 2011, sebanyak 268.439 Posyandu tersebar di seluruh Indonesia. Namun, bila ditinjau dari aspek kualitas, masih ditemukan banyak masalah di samping hanya terdapat sekitar 3 sampai 4 orang kader per posyandu keterampilan kader yang belum memadai. Ketrampilan tersebut berkaitan dengan penentuan status pertumbuhan Balita dalam Kartu Menuju Sehat dari hasil ploting berat badan balita (6).

Kader Posyandu atau kader gizi membantu ibu-ibu balita khusunya balita yang kurang gizi dan status gizi pendek (7). Dalam kegiatannya kader melakukan kegiatan di Posyandu melalui berbagai kegiatan meliputi pendaftaran,penimbangan, pencatatan, plotting dan konseling hasil penimbangan.

Sesuai dengan perkembangan ilmu pengetahuan dalam penentuan status gizi telah digunakan standar WHO 2005. Hasil penimbangan yang dilakukan oleh kader di plot di dalam KMS oleh kader. Apabila penimbangan dilakukan secara berturut-turut maka grafik akan bisa dibaca kecenderungan pemantauan pertumbuhan naik atau turun, namun didalam pelaksanaannya masih banyak kader yang masih belum memahami membaca mengenai kecenderungan grafik pertumbuhan.

\section{TUJUAN PENELITIAN}

Tujuan umum dari penelitian adalah untuk Hubungan antara Karakteristik (umur, tingkat pendidikan, lama menjadi kader yang aktif ), 
Sumber Informasi dan Pengetahuan terhadap Keterampilan Kader dalam Menentukan Titik Ploting pada Grafik Pertumbuhan Balita di RW 09 Ciracas Jakarta Timur. Sedangkan tujuan Khusus

a. Mengidentifikasi karakteristik kader (umur, tingkat pendidikan, lama menjadi kader)

b. Mengetahui sumber informasi yang diperoleh kader dalam menentukan grafik pertumbuhan

c. Menilai pengetahuan kader dalam menentukan titik ploting pada grafik pertumbuhan Balita

d. Menganalisis hubungan umur, tingkat pendidikan, lama menjadi kader dengan sikap kader dalam menentukan titik ploting pada grafik pertumbuhan Balita

e. Menganalisis hubungan pengetahuan kader dengan keterampilan kader dalam menentukan titik ploting grafik pertumbuhan Balita

\section{METODE PENELITIAN}

Penelitian ini dilakukan di Posyandu RW 09 Kelurahan Ciracas Kecamatan Ciracas Jakarta Timur. Penelitian ini merupakan penelitian survei, dengan pendekatan Cross Sectional dimana variabel terikat dan bebas diukur pada saat yang sama dan menurut kondisi pada saat itu.

Populasi penelitain adalah seluruh kader posyandu di RW 09 Kelurahan Ciracas Kecamatan Ciracas Jakarta Timur. Sedangkan sampel penelitian adalah

Tabel 1. Nilai Statistik Umur dan Lama

Menjadi Kader

\begin{tabular}{lcccc}
\hline $\begin{array}{l}\text { Karakteristik } \\
\text { Kader }\end{array}$ & $\begin{array}{c}\text { Rera } \\
\text { ta }\end{array}$ & Min & Maks & $\begin{array}{c}\text { Std } \\
\text { Dev }\end{array}$ \\
\hline $\begin{array}{l}\text { Usia Kader } \\
\text { (tahun) }\end{array}$ & 49.73 & 38 & 66 & 7.49 \\
$\begin{array}{c}\text { Lama Menjadi } \\
\text { Kader (tahun) }\end{array}$ & 10.18 & 1 & 31 & 6.95 \\
\hline
\end{tabular}

sebanyak 33 orang kader yang berada di RW 09 Ciracas Jakarta Timur yang diambil secaraPurposive Sampling.

Jenis data yang dikumpulan adalag data Primer maliputi Identitas kader yang terdiri dari nama, alamat, tanggal lahir, umur, tingkat pendidikan, lama menjadi kader, pengetahuan dan kterampilan kader dalam plotting berat badan. Sedangkan data sekunder tentang gambaran Posyandu RW 09 Ciracas seperti data kader poyandu yang aktif. Pengumpulan data dilakukan dengan menggunakan kuesioner dan lembar cek list observasi untuk keterampilan kader. Untuk menjawab tujuan penelitian maka analis data dilakukan secaraunivariate dan bivariat. Analisis Bivariat digunakan untuk menjawab tujuan yang ingin dicapai dalam penelitian dengan cara menganalisis hubungan umur, lama menjadi kader dengan sikap kader dalam menentukan titik ploting pada grafik pertumbuhan Balita, menganalisis hubungan antara sumber informasi dengan dengan pengetahuan kader dan menganalisis hubungan pengetahuan kader dengan dengan keterampilan kader dalam menentukan titik ploting pada grafik pertumbuhan Balita.

\section{HASIL DAN PEMBAHASAN}

\section{Karakteristik Kader}

Data Karakteristik Kader Posyandu RW 09 Ciracas Jakarta Timur yang dikumpulkan terdiri dari variabel jenis kelamin kader, usia kader, lama menjdi kader, tingkat pendidikan kader. Berikut merupakan hasil analisis data karakteristik kader Posyandu di RW 09, Ciracas Jakarta Timur dengan jumlah 33 kader Posyandu ditunjukkan Tabel 1.

Berdasarkan disribusi frekuensi karakteristik kader rata-rata usia kader Posyandu adalah 49.73 tahun dengan sebaran 7.49. lalu rata-rata lama menjadi kader adalah 10.18 tahun dengan sebaran 6.95. terlihat 
bahwa variasi usia kader lebih bervariasi jika dibandingkan dengan lama menjadi kader. Hasil ini sesuai dengan penelitian yang telah dilakukan peneitian terdahulu (7).

Berdasarkan tabel 2 distribusi frekuensi

Tabel 2. Distribusi Frekuensi Karakteristik Kader

\begin{tabular}{lcc}
\hline \multicolumn{1}{c}{ Karakteristik Kader } & $\mathrm{n}$ & $\%$ \\
\hline Jenis Kelamin & & \\
Laki-laki & 1 & 3.0 \\
Perempuan & 32 & 97.0 \\
Usia Kader & & \\
Dewasa Awal (26-35 tahun) & 0 & 0 \\
Dewasa Akhir (36-45 tahun) & 9 & 27.3 \\
Lansia Awal (46-65 tahun) & 17 & 51.5 \\
Lansia Akhir (56-65 tahun) & 7 & 21.2 \\
Lama Menjadi Kader & & \\
<3 tahun & 2 & 6.1 \\
3-5 tahun & 3 & 9.1 \\
6-8 tahun & 15 & 45.4 \\
9-11 tahun & 6 & 18.2 \\
>11 tahun & 7 & 21.2 \\
Tingkat Pendidikan & & \\
Tamat SD & 5 & 15.2 \\
Tamat SMP & 10 & 30.3 \\
Tamat SMA & 14 & 42.4 \\
Tamat Perguruan Tinggi & 4 & 12.1 \\
\hline
\end{tabular}

jenis kelamin kader Posyandu didapatkan hasil bahwa sebanyak 32 kader yang berjenis kelamin perempuan $(3.0 \%)$ dan 1 kader yang berjenis kelamin laki-laki (97.0\%). Sebagian besar kader Posyandu dalam distribusi umur kader (Tabel 2) terdapat pada kelompok lansia awal yaitu 17 kader (51.6\%), kemudian dewasa akhir sebanyak 9 kader $(27.2 \%)$, dan yang terakhir adalah lansia akhir dengan jumlah kader sebanyak 7 kader (21.2\%).

Dalam hal lama menjadi kader Posyandu (Table 3), sebagian besar yang sudah menjadi kader Posyandu yaitu antara 6-8 tahun sebanyak 15 (45.4\%), yang sudah >11 tahun sebanyak 7 kader (21.2\%), kemudian 9-11 tahun sebanyak 6 kader (18.2\%), dan $<5$ tahun sebanyak 5 kader (15.1\%). Hasil ini sesuai dengan penelitian yang dilakukan oleh (8) tentang pengetahuan anak sekolah dasar.

Pendidikan dapat mempengaruhi seseorang termasuk juga perilaku sesorang akan pola hidup terutama dalam memotivasi untuk siap berperan serta dalam pembangunan kesehatan. Jika dilihat berdasarkan tabel pendidikan terakhir kader (Tabel 2), sebagian besar kader merupakan tamatan SMA yaitu 14 kader (42.4\%), kemudian tamatan SMP yaitu 10 kader (30.3\%), lalu tamat SD sebanyak 5 kader (15.2\%) dan yang terakhir adalah tamatan Perguruan Tinggi sebanyak 4 kader (12.1\%). Dengan kader berpendidikan tinggi diharapkan lebih mudah untuk menerima suatu gagasan atau materi yang berhubungan dengan kegiatan Posyandu.

\section{Sumber Informasi}

Sumber informasi adalah segala sesuatu yang menjadi perantara dalam menyampaikan informasi. Tabel dibawah merupakan tabel frekuensi sumber informasi yang sering didapat oleh kader Posyandu, ditunjukkan Tabel 3

Tabel 3. Distribusi Frekuensi Sumber Informasi

\begin{tabular}{lcc}
\hline $\begin{array}{l}\text { Sumber Informasi } \\
\text { yang di dapat oleh }\end{array}$ & $\mathrm{n}$ & $\%$ \\
Kader & & \\
\hline Media Cetak & 1 & 3.0 \\
Media Elektronik & 9 & 27.3 \\
SDM (Sumber & 23 & 69.7 \\
Daya Manusia) & & \\
Total & 33 & 100 \\
\hline
\end{tabular}

Berdasarkan tabel di atas, frekuensi sumber informasi didapatkan hasil bahwa sumber informasi yang paling banyak diterima oleh kader adalah SDM (Sumber Daya Manusia) yaitu 23 kader (69.7\%), 
selanjutnya Media Elektronik sebanyak 9 kader $(27.3 \%)$ dan yang memilih media cetak 1 kader $(3.0 \%)$. Dari hasil tersebut banyak yang memilih SDM karena kader Posyandu setempat sering mendapatkan informasi dari tenaga kesehatan ataupun tetangga atau keluarga terdekat dibandingkan dengan media elektronik seperti internet dan media cetak seperti buku, booklet, leaflet,dll.

\section{Pengetahuan Kader}

Pengetahuan adalah hasil 'tahu' dan ini terjadi setelah orang melakukan penginderaan terhadap suatu objek tertentu. Pengetahuan atau kognitif merupakan domain yang sangat penting untuk terbentuknya tindakan seseorang (9). Dalam penelitian ini, didapatkan hasil pengetahuan kader Posyandu mengenai KMS (Tabel 4)

Berdasarkan tabel tersebut dapat dilihat bahwa kader yang berpengetahuan baik sebanyak 13 (39.4\%), kader yang berpengetahuan sedang sebanyak 15 kader $(45.5 \%)$ dan masih ada kader yang berpengetahuan kurang sebanyak 5 kader

Tabel 4. Distribusi Frekuensi Kader Menurut Pengetahuan Kader

\begin{tabular}{lcc}
\hline $\begin{array}{c}\text { Pengetahuan } \\
\text { Kader }\end{array}$ & $\mathrm{n}$ & $\%$ \\
\hline Baik & 13 & 39.4 \\
Sedang & 15 & 45.5 \\
Kurang & 5 & 15.2 \\
Total & 33 & 100 \\
\hline
\end{tabular}

Tabel 5. Distibusi Frekuensi Kader Menurut Pengetahuan Kader Berdasarkan Pertanyaan

\begin{tabular}{|c|c|c|c|c|c|c|c|}
\hline \multirow[t]{2}{*}{ No } & \multirow{2}{*}{ Pertanyaan } & \multicolumn{2}{|c|}{ Benar } & \multicolumn{2}{|c|}{ Salah } & \multicolumn{2}{|c|}{ Total } \\
\hline & & $\mathrm{N}$ & $\%$ & $\mathrm{n}$ & $\%$ & $\mathrm{n}$ & $\%$ \\
\hline 1. & Pengertian KMS & 18 & 54.5 & 15 & 45.5 & 33 & 100 \\
\hline 2. & $\begin{array}{l}\text { Menentukan KMS berdasarkan } \\
\text { jenis kelamin }\end{array}$ & 27 & 81.8 & 6 & 18.2 & 33 & 100 \\
\hline 3. & $\begin{array}{l}\text { Menentukan KMS berdasarkan } \\
\text { jenis kelamin }\end{array}$ & 28 & 84.8 & 5 & 15.2 & 33 & 100 \\
\hline 4. & $\begin{array}{l}\text { Menentukan perkiraan bulan anak } \\
\text { yang menimbang }\end{array}$ & 14 & 42.4 & 19 & 57.6 & 33 & 100 \\
\hline 5. & $\begin{array}{l}\text { Menentukan langkah pengisian } \\
\text { KMS setelah menimbang BB } \\
\text { anak }\end{array}$ & 24 & 72.7 & 9 & 27.3 & 33 & 100 \\
\hline 6. & $\begin{array}{l}\text { Pencatatan setiap kejadian yang } \\
\text { dialami anak }\end{array}$ & 12 & 36.4 & 21 & 63.6 & 33 & 100 \\
\hline 7. & $\begin{array}{l}\text { Pernyataan hasil setelah } \\
\text { menimbang BB jika BB tersebut } \\
\text { tidak naik }\end{array}$ & 20 & 60.6 & 13 & 39.4 & 33 & 100 \\
\hline 8. & $\begin{array}{l}\text { Pernyataan hasil setelah } \\
\text { menimbang BB jika BB tersebut } \\
\text { naik }\end{array}$ & 29 & 87.9 & 4 & 12.1 & 33 & 100 \\
\hline 9. & $\begin{array}{l}\text { Pemberian kapsul vitamin A pada } \\
\text { bayi yang berusia } 6-11 \text { bulan }\end{array}$ & 24 & 72.7 & 9 & 27.3 & 33 & 100 \\
\hline 10. & Pengertian ASI Eksklusif & 32 & 97.0 & 1 & 3.0 & 33 & 100 \\
\hline
\end{tabular}




\section{(15.2\%).}

Dari pertanyaan yang telah diberikan bahwa jika dilihat dari setiap soal masih ada beberapa kesalahan yang banyak diisi oleh kader hal tersebut dapat dilihat pada Tabel 5.

Rata-rata skor tingkat pengetahuan langkah pengisian KMS pada kader adalah 68.79. Nilai teerndah 20 dan nilai tertinggi 100. Tingkat pengetahuan dikatakan baik apabila nilai $\geq 80 \%$, dikatakan sedang 60 $80 \%$ dan dikatakan kurang apabila nilai $<80 \%$. Dengan demikian berdasarkan nilai

\section{Pengetahuan Kader berdasarkan Sumber Informasi}

Berdasarkan tabel 6 dapat dilihat bahwa pengetahuan kader yang sedang mendapatkan sumber informasi dari media yaitu 7 kader (63.6\%) dan lebih banyak banyak yang berasal dari non media yaitu sebanyak 17 kader $(77.3 \%)$. Sedangkan untuk pengetahuan yang baik lebih banyak yang mendapatkan sumber informasi berasal dari non media yaitu 5 kader $(22.7 \%)$ dan dari media

Tabel 6. Hubungan Sumber Informasi dengan Pengetahuan Kader

\begin{tabular}{lcccccc}
\hline \multirow{2}{*}{ Sumber Informasi } & \multicolumn{4}{c}{ Pengetahuan Kader } & \multicolumn{2}{c}{ Total } \\
& \multicolumn{2}{c}{ Sedang } & \multicolumn{2}{c}{ Baik } & & \\
& $\mathrm{N}$ & $\%$ & $\mathrm{n}$ & $\%$ & $\mathrm{~N}$ & $\%$ \\
\hline Media & 7 & 63.6 & 4 & 36.4 & 11 & 100 \\
Non Media & 17 & 77.3 & 5 & 22.7 & 22 & 100 \\
Total & 24 & 72.7 & 9 & 27.3 & 33 & 100 \\
\hline
\end{tabular}

rata-rata, tingkat pengetahuan kader mengenai langkah-langkah pengisian KMS tergolong sedang (10).

Berdasarkan tabel distribusi frekuensi pengetahuan pertanyaan diatas, pertanyaan yang paling banyak dijawab dengan benar yaitu pertanyaan nomor 3,8 dan 10 masingmasing pertanyaan mengenai menentukan KMS berdasarkan jenis kelamin, menentukan hasil status pertumbuhan anak dan pegertian ASI Eksklusif. Untuk pertanyaan yang dijawab salah paling banyak pada pertanyaan nomor 6 dengan pertanyaan mengenai pencatatan hal setiap kejadian anak (11). sebanyak 4 kader (36.4\%).

Dari hasil uji statistik Chi-Square diperoleh nilai $\mathrm{p}=0,43$ dengan $\alpha=0,05$, yang berarti tidak ada hubungan antara sumber informasi dengan pengetahuan kader. Namun ada kecenderungan bahwa tingkat pengetahuan kader yang sedang lebih banyak mendapatkan sumber informasi berasal dari non media. Penelitian ini sesuai dengan penelitian lain yang menunjukkan bahwa sumber informasi mempengaruhi pengetahuan kader (8).

Tabel 7. Hubungan Pengetahuan Kader dengan Keterampilan Kader

\begin{tabular}{lcccccc}
\hline & \multicolumn{3}{c}{ Keterampilan Kader } & \multicolumn{2}{c}{ Total } \\
Pengetahuan Kader & Tidak Terampil & Terampil & & \\
& $\mathrm{N}$ & $\%$ & $\mathrm{n}$ & $\%$ & $\mathrm{n}$ & $\%$ \\
Sedang & 19 & 79.2 & 5 & 20.8 & 24 & 100 \\
Baik & 3 & 33.3 & 6 & 66.7 & 9 & 100 \\
Total & 21 & 63.7 & 11 & 33.3 & 33 & 100 \\
\hline
\end{tabular}




\section{Keterampilan Kader berdasarkan Pengetahuan Kader}

Berdasarkan Tabel 7 menunjukkan bahwa ketidak terampilan kader menurut pengetahuan kader yang sedang lebih banyak dibandingkan dengan pengetahuan kader yang baik. Untuk pengetahuan kader yang sedang berjumlah 19 kader (79.2\%), untuk tingkat pengetahuannya baik berjumlah 3 kader (33.3\%). Dan untuk yang terampil lebih banyak kader yang memilliki tingkat pengetahuan yang baik dengan jumlah 6 kader (66.7\%), kemudian tingkat pengetahuan sedang yaitu 5 kader $(20.8 \%)$.

Dari hasil uji statistik Chi-Square diperoleh nilai $\mathrm{p}=0.05$ dengan $\alpha=0,05$, yang berarti ada hubungan antara pengetahuan kader dengan keterampilan kader.Hasil tersebut sama dengan penelitian yang dilakukan oleh (12) menyatakan bahwa adanya hubungan antara pengetahuan dengan parktik kader dalam pelaksanaan kegiatan Posyandu dengan nilai $\mathrm{p}$ value sebesar 0.003 .

\section{SIMPULAN}

Berdasarkan jenis kelamin, sebagaian besar dengan jumlah 32 kader $(97.0 \%)$ berjenis kelamin perempuan dan hanya 1 kader (3.0\%) yang berjenis kelamin laki-laki dari 33 kader Posyandu, Sedangkan berdasarkan usia kader, yang paling banyak berada di kategori lansia awal (46-65 tahun) yaitu sebanyak 17 kader (51.3\%), yang kedua adalah dewasa akhir (36-45 tahun) sebanyak 9 kader $(27.3 \%)$ dan yang terakhir lansia akhir (56-65 tahun) dengan jumlah 7 kader (21.2\%). Kader telah lama menjadi kader antara 6-10 tahun dengan jumlah kader 19 kader $(57.6 \%)$, kemudian $>10$ tahun yaitu 9 kader $(27.3 \%)$ dan $<5$ tahun sebanyak 5 kader (15.2\%). Tingkat pendidikan kader posyandu, sebanyak 15 (44.1\%) kader tamat pendidikan dasar, 14 kader tamat pendidikan SMA (44.1\%), 4 kader (11.8\%) tamat Perguruan Tinggi. Sumber informasi yang didapat oleh kader lebih banyak berasal dari SDM (Sumber Daya Manusia) yaitu sebesar 23 kader $(69.7 \%)$, kemudian media elektronik dengan jumlah 9 kader $(27.3 \%)$ dan media cetak 1 kader $(3.0 \%)$. Tingkat pengetahuan kader, sebanyak 5 kader (15.2\%) kurang, kemudian 15 kader (45.5\%) dengan tingkat pengetahuan sedang dan 13 kader (39.4\%) dengan tingkat pengetahuan baik. Dari hasil analisis bivariate menunjukkan bahwa adanya hubungan yang signifikan antara keterampilan kader berdasarkan pengetahuan kader.

\section{UCAPAN TERIMA KASIH}

Terima kasih kami ucapkan kepada para kader Posyandu di Kecamatan Ciracas yang telah membantu dalam kelancaran pengumpulan data. Kepada pihak kecamatan dan Kelurahan yang telah memfasilitasi terlaksananya penlitian kami mengucapkan banyak terima kasih.

\section{DAFTAR PUSTAKA}

1. Indonesia R. Undang-Undang tentang Perlindungan Anak. 2002.

2. Sofyawati. Hubungan Pengetahuan Ibu Dengan Peningkatan berat Badan Pada Balita. Universitas Indonesia; 2013.

3. Badan Penelitian dan Pengembangan RI. Laporan Riset Kesehatan Dasar. Jakarta; 2013.

4. Ferguson LR, Caterina D, Görman U. Guide and Position of the International Society of Nutrigenetics / Nutrigenomics on Personalised Nutrition: Part 1 Fields of Precision Nutrition. 2016;12 27.

5. Fitriyah Z. Peran Serta Kader Posyandu Dalam Upaya Peningkatan Status Gizi Balita di Posyandu. Jakarta; 2011.

6. Azwar A. Pedoman Umum Pengelolaan Posyandu. Jakarta: Kementerian Kesehatan RI; 2006. 
7. Rokhmah D. Strengthening Community Food Security through Posyandu Cadre and Midwife Empowerment Action Program. 2015;5(3):234-7.

8. Parisa K, Seyed MM, Zahra M, Zainab $\mathrm{H}$, Najmeh M, Mirshekari M. Effect of a School-based Nutrition Education Program on the Nutritional Status of. Nutr Food Sci Res. 2016;3(1):27-34.

9. Rahman N, Nurul R. Mothers , Participation and Compliance toward the Improvement of the Infants ' Nutritional in Community Feeding Center Lagarutu Palu. 4531:136-49.

10. Feleke BE. Nutritional Status and Intestinal Parasite in School Age Children: A Comparative CrossSectional Study. 2016;2016:23-8.

11. Lee J, Jeong S, Ko G, Park H. Development of a Food Safety and Nutrition Education Program for Adolescents by Applying Social Cognitive Theory. 2016;7(4).

12. Fitri H. Pelatihan Terhadap Keterampilan Kader Posyandu. Depok; 2011. 